\title{
Revitalising an academic pathology department: lessons learnt
}

\author{
Zu-hua Gao, Edith Zorychta, Jason Karamchandani, René P Michel, Fadi Brimo, \\ Carlos Telleria, Sophie Camilleri-Broët, Manon Auger, Van-Hung Nguyen, Alan Spatz
}

Department of Pathology, McGill University and MGill University Health Center, Montreal, Quebec, Canada

\section{Correspondence to} Dr Zu-hua Gao, Department of Pathology, McGill University, Montreal, Quebec H4A 3J1, Canada; zu-hua.gao@mcgill.ca

Received 20 September 2018 Accepted 28 October 2018 Published Online First 22 November 2018

Check for updates

(c) Author(s) (or their employer(s)) 2019. No commercial re-use. See rights and permissions. Published by BMJ.

To cite: Gao Z, Zorychta $\mathrm{E}$, Karamchandani J,

et al. J Clin Pathol

2019:72:213-220

\section{ABSTRACT}

Pathology is a specialty that bridges basic medical science and clinical practice. In the era of personalised medicine, this specialty is facing unprecedented challenges. Some of these challenges are institutionspecific, while many are shared worldwide at different magnitude. This review shares our team efforts in the past 5 years, 2012-2017, to revitalise a century-old academic pathology department in three aspects: administration, clinical service and academic development. The lessons learnt and insights gained from our experience may provide guidance to leaders in pathology or in other related specialties.

\section{HISTORY AND BACKGROUND INFORMATION}

Established in 1892, the Department of Pathology at McGill University has been one of the most reputable academic pathology departments in North America. Many outstanding individuals have worked and studied in the department, including Sir William Osler, frequently described as the 'father of modern medicine', Dr. Maude Abbott, renowned pioneer in cardiovascular research and one of the first female physicians in North America and Dr John McCrae, author of the famous war poem 'In Flanders Fields'. The department has a wealth of documents, specimens and educational materials, some of which are now housed in the Maude Abbott Medical Museum. ${ }^{1-3}$

The 'Pathology Institute', as part of the Royal Victoria Hospital complex, came into being in 1923 with building funds from the J.D. Rockefeller Foundation. In the 1960s, the Pathology Institute was expanded by the construction of the Lyman Duff Medical Sciences Building, located next to the Royal Victoria Hospital. In May 2015, the pathology laboratories of the Royal Victoria Hospital, Montreal General Hospital (MGH), Montreal Children's Hospital and Montreal Chest Institute were centralised and relocated to the McGill University Health Center (MUHC) Glen Campus. The department provides service to a population of nearly two million people who receive clinical care in one of the McGill-affiliated hospitals. ${ }^{1-3}$ The department has an annual activity of about 200000 surgical pathology samples, 170000 cytology tests, 350 adult autopsies and 200 paediatric autopsies.

The department currently includes 56 professors, 12 associate members, 23 residents, 2 clinical fellows, 30 graduate students and over 350 supporting staff (technologists, pathologists' assistants and secretaries). Faculty members in the department teach $6 \%$ of the undergraduate medical and dental curriculum of the McGill University Faculty of Medicine and Dentistry, a full course in pathology for advanced students in biomedical sciences and healthcare professions and nine graduate level courses in specialised areas of research on diseases. ${ }^{1}$

In Quebec, pathologists currently are paid on a fee-for-service model based on a system of units associated with the complexity of the specimen. ${ }^{4}$ Postgraduate resident education is supported by the provincial government. The university provides some support for undergraduate and graduate education. PhD scientists are university employees, but their research operating costs are funded by grants. The Quebec sovereignty movement in the late 20th century had a negative impact on the provincial economy, which further negatively impacted university funding and academic support to individual faculty members. ${ }^{5}$

\section{REALITY CHECK AND ICE-BREAKING EXERCISE}

In the fall of 2012, a one-on-one meeting was conducted between the new chair and each medical and scientific staff member in the department, all technical leaders, residents and graduate students, the dean of medicine, the hospital director of professional services, other department chiefs and potential donors (foundations and alumni). The questions asked by the chair were: What is working? What is not working? What should be our immediate priorities? What should the goals be over the next 5 years and how can they be achieved? The main findings from these consultations were as follows:

On the administrative front, unclear management structure, lack of departmental policy, staff shortage due to suboptimal recruitment and retention, collegiality issues, a difficult financial situation and suboptimal communication were identified as the main issues.

On the clinical front, workload increase and staffing shortage, inefficient workflow with significant backlogs, laboratory underfunding and repeated budget cuts imposed by the provincial government, inadequate specimen grossing due to deficient training and coordination of pathologists' assistants and the lack of a robust quality assurance (QA) and risk management process were identified as the main issues.

On the academic front, the diminishing graduate education programme, the sustainability of the residency-training programme, the lack of a funded clinical fellowship programme, the reduction of 
research capacity and output, the lack of structural and financial support for research activities were the major concerns.

When we analysed the situation, most of the issues identified were at the system level rather than at the individual level because the quality of most staff members' work was high. There were potential leaders or actual star performers in different areas, and most people wanted change and were willing to contribute.

After the fact-finding exercise, we organised a 2-day departmental retreat. During that first retreat, the Chair delivered his assessment of the reality, moderated discussion on strategic solutions, on defining the department's values and setting the direction based on the department's shared vision. The clinical quality assurance director presented a gap analysis with the best practice guidelines. Education and research leaders presented a Strength-Weakness-Opportunity-Threat (SWOT) analysis of their respective domains. During that first retreat, we jointly crafted our vision, mission, 5-year goals and strategy and practical plans for the first year. We assigned teams and team leaders for each one of the strategic priorities identified. We also made plans to monitor our progress, address issues as they arose and modify our approaches when needed. This event brought medical scientific staff from different sites together and facilitated the development of cross-site subspecialty interest groups to jointly set practice standards, coordinate teaching activities and conduct research projects.

Lessons learnt:

1. Listening and asking the right questions. People on the ground know the real problems and can suggest solutions. Listening is also a powerful motivational tool.

2. Carefully analysing the information gathered can discover the root cause of the problem and find potential solutions to the problem.

3. Setting the stage for establishing a shared vision. Rebuilding a department will only work if the vision, goals and plans come from the entire team and everybody has played an integral role in the process.

\section{ADMINISTRATION Departmental governance}

A pathology department must have a governing body with clear rules and responsibilities and a well-written departmental policy to set the norms and procedures. Working with departmental members, we revamped departmental policies to clearly outline the department's expectations for pathologists regarding clinical service, teaching, research, attendance at meeting and vacation. The policy was communicated to all departmental members, including new recruits.

We clarified the reporting structure and developed terms of reference for the key administrative positions in the department including the director of surgical pathology, director of quality assurance, directors of undergraduate, graduate and postgraduate education and director of research. Department leaders have a strategic focus on quality, efficiency, academic development, workload/staffing and external relations. Specialty group leaders are responsible for setting up practice standards, implementing QA processes, coordinating teaching and research activities and communicating with clinicians on issues related to their specialty. We used our practice plan, which is pooled clinical income, to provide a small stipend for some of the key administrative positions in the department.

We established a departmental academic committee, a clinical operations committee, a quality assurance committee, a teaching committee and a research committee. All committees have clear terms of reference and hold regular meetings. We ensure that decisions made in those committee meetings are communicated to the staff in a timely, transparent fashion. We have incorporated policy review sessions in departmental meetings.

Lessons learnt:

1. Having an organisational chart clarifies the reporting structure and having well-documented terms of reference clarifies the roles and responsibilities for each position.

2. To create an enabling environment, the chair should grant autonomy to the leaders and provide support but demand accountability to ensure they deliver the expected results.

3. All stakeholders should be involved in drafting departmental policies. Once the policy is finalised, it must be communicated effectively in a multisite setting. People should be held accountable when rules are not followed.

4. Regular staff meetings and retreats are good venues for discussing strategic directions and addressing department-wide issues and concerns.

\section{Recruitment and retention}

Recruitment and retention of the best people are critical for the success of any department. Once the right people are on the bus, it will go in the right direction. ${ }^{6}$ The challenges we faced were: (1) relatively higher workload and lower income than Canadian average, ${ }^{78}$ (2) pathologists' fear/reluctance of diluting their income if new pathologist was recruited under the Quebec fee-for-service billing structure (3) unwillingness of some pathologists to share their specialty (4) lack of collegiality and academic support for newly recruited staff and (5) the complex and lengthy recruitment process, particularly for recruits coming from outside Canada.

We streamlined the recruitment process. Working with the MGH and the Jewish General Hospital (JGH) foundations, we were able to secure start-up research funding for all newly-recruited pathologists and scientists in the amounts ranging from $\$ 30000 /$ year to $\$ 100000 /$ year for 3 years. Since 2013, we have recruited 18 pathologists ( 8 were replacement positions) and 4 $\mathrm{PhD}$ scientists into the department. Some of the new recruits have become the backbone of the department in research, education and clinical service.

Lessons learnt:

1. Finding the right people. Diagnostic skills, collegiality and academic potential are our primary considerations for recruitment.

2. Provide support for the new recruits. In addition to providing start-up research funds, facilitating the establishment of research collaborations with established programme is an effective strategy for retention.

3. Advocate, recognise and promote excellence. Some new recruits in our department were rapidly promoted to associate professors and were appointed into key leadership positions such as director of the residency training programme, director of surgical pathology and director of research.

\section{Budget management and fundraising}

A healthy budget is critically important for accomplishing the academic mission of the department. With support from the dean, we redirected the use of over half a million Canadian dollars from the university each year for academic purposes. The funds were used for salary to support the recruitment of two research scientists, for undergraduate education as stipends for lectures and small group teaching, for graduate education as financial support for MSc and $\mathrm{PhD}$ students and as incentives for researchers to accept graduate students. In addition, an annual 
research competition was held to fund five internal research projects per year.

Working with industry and the Rossy Cancer Network, ${ }^{9}$ we raised funds to support an annual departmental retreat and a monthly scientific lecture series. With the approval of staff pathologists at MUHC, we took $2 \%$ of pooled practice plan clinical income to support administrative stipends for subspecialty directors and the residency programme director, to support the academic expenses of our residents (eg, attending and presenting at conferences, attending review courses) and funded one clinical fellowship position per year at the MUHC.

Starting from no financial support, our graduate programme raised over $\$ 500000 /$ year from different sources to sustain a graduate programme of over 30 graduate students. In addition to obtaining support from the practice plan, our resident training programme secured over $\$ 200000$ from the hospital education fund and the university postgraduate education fund.

Working with the Cedars foundation and the Royal Victoria Hospital foundation, we were able to secure funds to purchase next generation sequencing (Miseq) equipment and the comparative genomic array (CGH) platform. Working with the JGH Foundation, we were able to raise 9 million Canadian dollars to build a cutting-edge McGill Molecular Pathology Center (MPC) with equipment including NanoString nCounter, two miSeq, two Ion GeneStudio S5 XL series, a cell culture facility platform associated with the MPC and to completely renovate the JGH Pathology laboratory. Thanks to an endowment of 3.6 million dollars from Dr Nunes Collins, a highly successful pathologist who began her career at McGill, the department was able to establish the Dr. Nunes Collins endowed Chair in pathology.

Overall, the department raised 15.5 million dollars in addition to the half a million dollars per year from the university. The healthy financial outlook of the department helped us to expand our research capacity and advance our educational agenda.

Lessons learnt:

1. Assertive approach. We have aggressively reached out to potential donors in the community, alumni, foundations and industry, ensuring that they understand the critical role of pathologists in patient care and that every dollar they donate to pathology is used for the intended purpose of improving the lives of our patients.

2. Innovative approaches. These included writing emails, letters, writing applications, sending Christmas cards, making presentations to the board of hospital foundations and through personal connections. We recently approached Chinese universities in a proposal to raise funds by offering teaching and collaborative research support.

3. A culture of giving. Our pathologists were very generous in giving $2 \%$ of their clinical income to support resident education, a clinical fellowship programme and a small stipend for key leadership positions in the department.

\section{Establishing a healthy departmental culture}

Workplace culture is a determining factor for the success of any organisation. A healthy culture in the workplace gives the employees a sense of unity and consideration towards each other, promotes better communication, less conflict, breeds loyalty and helps in recruitment and retention. Dysfunction can lead to high staff turnover, overall malaise and poor performance for the department at both the clinical and academic levels. The challenges facing our department were (1) staff fatigue and irritation due to high clinical workload (2) lack of collegiality between some medical and scientific staff and between some medical or scientific staff and support staff (3) high expectations for academic performance but without protected time or support for academic work (4) lack of transparency in the decision-making process and inadequate transmission of information and (5) positive behaviours were not acknowledged and there were no consequences for negative behaviours.

To create a sense of shared purpose, we engaged all stakeholders to establish a shared vision during our first departmental retreat and communicated our strategic direction to all members of the department. We established two annual awards: the collegiality award and the innovation award. The former is given to the person who goes the extra mile to help colleagues, builds teams, organises and participates in activities that benefit everybody and promotes a respectful and supportive environment. The innovation award is given to the person whose creativity improves the system beyond their daily job requirements, which effectively turned complaints into constructive thinking and process improvement actions. Every year, at least one person is chosen for each award category; this has become a major event at the annual MUHC Christmas party. When there is a conflict between departmental members, we try to understand the underlying concerns of both sides and facilitate a collective negotiation using a variety of methods including negotiation, mediation, arbitration, diplomacy and creative peace building. ${ }^{10} 11$

To improve communication, several strategies were implemented including (1) a weekly management meeting with minutes circulated to all staff members; (2) a monthly staff meeting; (3) a quarterly departmental newsletter; (4) an annual departmental retreat and an annual research day; (5) a departmental web site with a news section. These measures have facilitated collaboration within and outside the department.

In our department, the performance metrics were drafted by the academic committee, communicated to all staff members and approved by the associate dean of academic affairs. The metrics differ for scientific research faculty versus clinical pathologists. Among clinical pathologists, the expectations are different for clinician-scientists, clinician-educators and clinician-administrators. These metrics are sent to the staff with a self-evaluation form before the annual performance evaluation to allow staff members sufficient time for self-assessment. The Chair assigns a rating during a discussion with the employee to ensure that excellence is acknowledged, deficiencies addressed and career development plans are made in a positive environment. We also used performance review sessions to evaluate the Chair's own performance and received many constructive comments on how to effectively manage the department.

To promote an academic culture, we established a monthly scientific lecture series and an annual research competition. We award the best staff pathologist teachers, best residents and best resident teachers every year. We also established a Chair's award for trainees who have platform presentations at international venues. These cultural changes have gradually improved staff members' satisfaction at the workplace, facilitated better recruitment and retention and improved the academic productivity.

Lessons learnt:

1. The culture rests with the leader of the department, particularly the Chair, who must have high expectations for performance and results and show genuine concern for all stakeholders. $^{12}$

2. Including departmental members in the decision-making process, encouraging their creativity and trusting their judgement improves job satisfaction and productivity.

3. Pathologists' resistance to change tends to be 'passive-aggressive' and reaching out to the resistors is imperative to under- 
stand their real concerns. Sometimes feedback from resistors can help initiate acceptance of change.

4. The importance of communication cannot be overemphasised. Most of the issues we experienced were largely due to poor communication.

5. Departmental social events such as a retreat and award ceremony can help create pride in the workplace and attract good people into the workforce.

\section{CLINICAL SERVICE \\ Quality of service}

The quality of pathology service rests on each step of the workflow from sample request to delivery of the result. Poor understanding of the nature of pathology service and unrealistic demands by the general public and some healthcare administrators, workforce shortage, insufficient resources for QA (eg, IT support), the need to provide quality service to remote regions, subjectivity and the lack of a gold standard in the specialty are common problems facing many academic pathology departments around the world. ${ }^{13}$ As a multisite clinical department, one of our challenges is the lack of standardisation across hospital sites because each hospital site has a separate pathology laboratory with its own laboratory information system, its own standard operating procedures (SOPs) and QA manuals. Specimen grossing protocols differ between hospital sites and consequently, the number of tissue blocks submitted for the same type of specimen varies at the different locations.

In our department, the quality assurance (QA) committee is chaired by the director of QA and composed of service chiefs at each hospital site, the director of the ancillary testing laboratory and the manager of technical operations. To improve quality, our QA committee conducted gap analysis between our departmental SOPs and the best practices of the Johns Hopkins Hospital, the Mayo Clinic and the Brigham and Women's Hospital. We standardised grossing templates for all specimens across all hospital sites. We updated our special stain and immunohistochemistry menu lists with on-slide controls. The pathologists work on a largely subspecialty-based practice model in which most subspecialties are covered by two or three pathologists and most pathologists cover two or three subspecialties. We have implemented synoptic reporting for all cancers and some non-neoplastic entities. Critical diagnoses are communicated verbally to treating physicians and documented on the report. All diagnoses that have a significant impact on clinical management are reviewed in 'tumour boards' and specialty clinical-pathology conferences. Lessons learnt:

1. The Chair must advocate for the specialty and be actively involved in resource planning and the decision-making process within the hospital and the university to ensure the department has appropriate resources.

2. Each pathology department should have a quality assurance committee responsible for developing standard policies and procedures across different hospital sites, managing incidents, implementing new quality improvement initiatives and laboratory accreditation.

3. In a large centre, a subspecialty practice model with frequent clinical-pathological communication improves the accuracy and clinical relevance of pathological diagnoses.

\section{Efficiency of service}

To improve efficiency, we centralised pathology laboratories from three hospital sites (Royal Victoria Hospital, Montreal General Hospital and Montreal Children's Hospital) to the MUHC Glen campus and automated our platforms wherever possible such as for staining and immunohistochemistry. ${ }^{14} 15$ All molecular testing laboratories including molecular pathology, molecular haematology, molecular microbiology and cancer cytogenetics were centralised to a core molecular biology facility, which reduced the cost of repetitive instruments and reagents in isolated settings and facilitated a standardised process with improved quality. To appropriately use laboratory resources, we advised our pathologists and residents not to order unnecessary immunohistochemical stains and our pathologists' assistants were taught not to submit unnecessary tissue blocks during specimen grossing. ${ }^{16}$ To remove non-value-added activity and to reduce variations, we designed the workflow of the MUHC pathology laboratory at the Glen site according to the Lean/Six Sigma concept. ${ }^{17}$ We adopted voice recognition, which essentially eliminated typing of gross descriptions and most of the pathology reports. ${ }^{18}$ We implemented Rapid On Site Evaluation (ROSE) for EBUS-FNA and for EUS-FNA cytology. Using a 'pay for performance' approach, we cleared all backlogs in autopsy and surgical pathology. ${ }^{19}$ Using the combination of centralisation, automation, lean and appropriate laboratory utilisation approaches, we were able to achieve over $20 \%$ budget savings in 3 years.

Lessons learnt:

1. Both pathologists and treating clinicians need to be educated on the appropriate utilisation of laboratory services and the elimination of unnecessary tests. ${ }^{16}$

2. Centralisation and complete automation are effective tools to improve efficiency. ${ }^{14} 15$

3. Lean Six Sigma is an effective methodology that can be used to design laboratory workflow and standardise the operating procedures across multiple hospital sites. ${ }^{17}$

4. Pathology leaders need to adopt some business ways of thinking, such as 'pay for performance' concept to manage clinical operations. ${ }^{19}$

\section{EDUCATION}

\section{Undergraduate medical sciences education}

Basic scientists in our department teach an upper level course in pathology (PATH300-Human Disease) to over 300 biomedical science students each year, consisting of 39 hours of lectures plus small group tutorials. Pathologists and pathology resident in our department teach $6 \%$ of the undergraduate medical and dental curriculum at McGill University, consisting of 46 lecture hours and over 900 small group teaching hours. Our unique challenges were to (1) preserve pathology teaching in the more clinically focused problem-based teaching curriculum (2) reward staff members for undergraduate teaching under the fee-for service clinical payment structure and (3) ensure that the quality of teaching exceeds the accreditation requirements. ${ }^{20} 21$ Our pathology undergraduate medical education director sits on the committees to ensure that the teaching of pathophysiology of disease is an integral part of the teaching curriculum and conform to the standards of the Committee on Accreditation of Canadian Medical Schools (CACMS). ${ }^{22}$ We initiated 'pathology consultations' during anatomy laboratories for first year medical students. We developed a new course, Putting It All Together (PIAT) titled Pathology for Medical, Radiation and Oncologists, for the fourth year medical students. We organised career day and pathology laboratory tours every year to ensure students understand the important role that pathologist plays in patient care so that we can attract talented students to a career in pathology. Exposure of biomedical science students to advanced pathology teaching at the early stage resulted in a constant enrolment of 

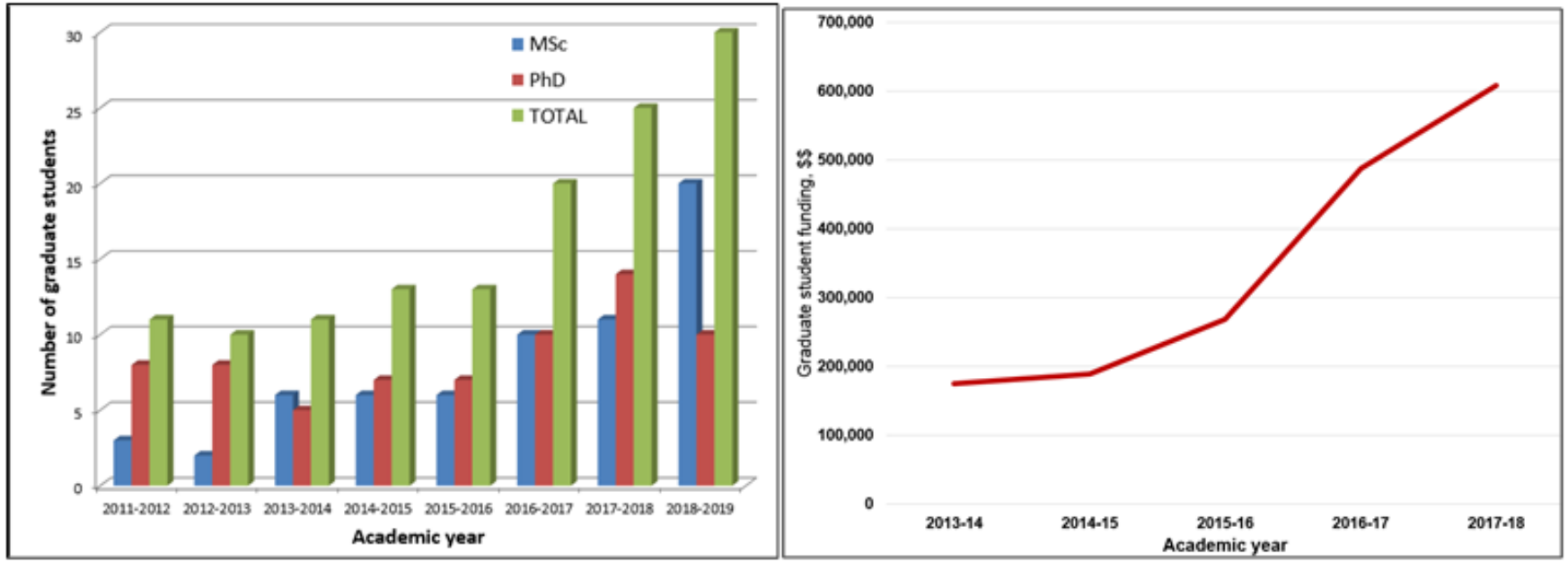

Figure 1 Significant increase in the number of graduate students (left) and funding for graduate students(right) in the past 5 years.

some of the best students into our graduate study programme and our residency training programme. According to the 2014 Association of Faculties of Medicine of Canada (AFMC) graduation questionnaire, McGill pathology undergraduate teaching has been consistently rated better than other medical schools in Canada $(4.2 / 5$ vs the national average of $3.5 / 5) .^{23}$

Lessons learnt:

1. Pathology teachers must be present at the drawing board during curriculum design to ensure that the content of pathology and pathophysiology teaching is sufficient and relevant to the understanding of the biology of disease.

2. A department needs mechanisms to reward pathologists' time and effort in undergraduate education.

3. The more exposure to pathology, the more likely students will choose a career in pathology.

\section{Graduate education}

The success of a graduate education programme is heavily linked to the number and quality of researchers in the department. Our Graduate Studies Programme was down to 8 students in 2012, and it was suggested by the faculty that we merge with larger programme such as Experimental Medicine or Oncology, thereby relinquishing our identity. To revitalise the pathology graduate programme, we (1) recruited four full-time $\mathrm{PhD}$ research scientists; (2) invited 12 prominent investigators doing disease-related research in other departments to become associate members in pathology so that they could supervise graduate students registered in our graduate studies programme; (3) recruited an experienced coordinator for the programme; (4) updated our departmental website to improve visibility and facilitate online applications; (5) secured over \$100 000 in hard funding and (6) facilitated and supported our students' applications for external funding from a variety of sources, both within Canada and from other countries.

With the expansion of the department's research capacity, our graduate programme was able to regrow to 30 students by 2018 (figure 1). The size of our graduate programme is now large enough to provide diversity and yet small enough to allow close interaction with personalised attention throughout the entire course of their training. Our programme attracts many qualified applicants and the acceptance rate is less than $20 \%$. Since pathology includes many subspecialties, our students have the opportunity to choose their thesis topic from a variety of areas, including cancer and cell biology, cardiovascular and airways disease, neurological disorders, immunology and transplantation, autoimmune disorders and disorders of vision. Following the 12 guiding principles of the Canadian Association of Graduate Studies, each student in our programme has a personalised research advisory committee consisting of the research director and often a codirector, plus two research advisors, one usually from another biomedical science department. ${ }^{24}$

Our graduate education committee led by the graduate programme director works with each graduate student and each supervisor to ensure that the students advance as expected in terms of their course credits, research projects and thesis work. We also provide advice and assistance to our students to ensure that they all have a productive career after graduation. None of our students have dropped out and all our graduates have succeeded in pursuing rewarding careers. Our students have won a variety of awards and scholarships during their graduate studies and their postgraduate careers predominantly include academic appointments, government agencies, medicine, administration, pharmaceutical and biotechnology industries.

Lessons learnt:

1. In addition to hiring new $\mathrm{PhD}$ scientists, having cross-appointed scientists as graduate student supervisors could increase the number of graduate students and provide a cross-disciplinary research environment.

2. Having a designated administrator for graduate studies who can update the website, assess applications, coordinate courses and student evaluations is critical to the success of the programme.

3. Graduate programme should include training in communication and career counselling to ensure students are well prepared for a successful career.

\section{Postgraduate medical education}

McGill has the second largest anatomical pathology residency training programme in Canada with full accreditation by the Royal College. Our challenges were: (1) insufficient funding from the university to support a programme director; (2) insufficient funding for resident academic activities such as attending conferences and conducting research projects; (3) compliance with the new 'competency-based residency training' mandate set by the Royal College; ${ }^{25}$ (4) attract the best candidates into our programme and (5) ensure our residents are trained in the use of new technologies and laboratory management skills. 


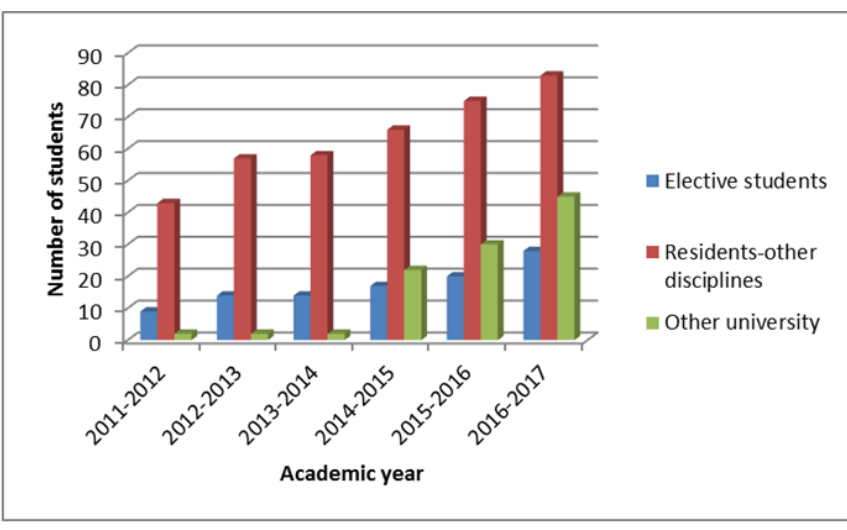

Figure 2 Steady increase of elective students and rotating residents from local, national and international sources

Additional resources were needed to implement the mandate of 'competency-based resident education'. We freed our programme administrator to focus exclusively on postgraduate training by transferring the responsibilities of graduate education to a dedicated secretary. We appointed an assistant programme director. Chief residents and senior residents who are interested in pathology education are all involved in the design and implementation of the new curriculum. Since there was insufficient funding from the university to support the programme, we used our practice plan to provide an additional stipend for our programme director, to purchase furniture for the resident rooms and to support our residents attending conferences, review courses and conducting research projects. In addition to structured weekly half-day teaching, our resident training programme committee implemented (1) a 'multiple mini interview' process during resident matching to help select the best candidates; ${ }^{26}(2)$ a 'transition to pathology' rotation for first year residents to quickly familiarise them with the laboratory environment and normal procedures; ${ }^{26}$ (3) a 'transition to practice rotation' for our senior residents, which has proven to be effective in improving residents' competency and readiness for practice in the real world; (4) a structured resident assessment system that includes an annual 'mock-oral' examinations, the American RISE examination, an exit rotation evaluation and an annual in-service examination; (5) intraoperative diagnosis workshops to train our residents in handling fresh specimens, sampling cutting and staining frozen sections and effectively communicating with surgeons; (6) new courses in quality assurance, laboratory management, molecular pathology and bioinformatics; (7) research projects on molecular diagnostics and quality improvement and (8) an annual resident retreat. We gradually established a national and international reputation in postgraduate pathology education. As a result, there has been a steady increase in the number of elective medical students from Canada and other countries, clinical residents from the McGill system and pathology residents from other universities coming to our department (figure 2). We presented our postgraduate teaching and matching experiences at the Canadian national pathology meeting. ${ }^{26} 27$ Our residents started producing high impact publications and winning awards at national (CAP) and international (USCAP) meetings. ${ }^{28} 29$

Thanks to the financial support provided by MUHC pathologists, our department established funded clinical fellowship programme in Royal College Areas of Focused Competence in Cytopathology (AFC-cyto), gastrointestinal and liver pathology and in hematopathology. Five clinical fellows have graduated from our department since 2013. We officially launched the mentorship programme in the department in 2015 to guide career development for our residents and junior faculty members. Formal career lectures were given by the chair and mentoring was given by senior pathologists on ad hoc basis. Quality of teaching is an important parameter in our annual performance evaluation. Faculty members in our department are encouraged to attend courses to improve their teaching skills. We also implemented 'how to teach' lectures in our resident training programme, in parallel with the 'how to do a scientific presentation' training in our graduate programme.

Lessons learnt:

1. The chair must ensure that resources (funding, secretarial) are available to support the programme director and residents.

2. Residents and trainees can be the driving force of innovation in postgraduate education.

3. 'Competency-based residency training' requires us to have a completely new approach to training and evaluating our residents to ensure that they become competent pathologists after graduation.

\section{Education projects}

During the era of Maude Abbott and William Osler, the McGill Department of Pathology established an impressive collection of gross specimens in glass jars, initially for education and later for a museum. Thanks to the financial support provided by the MGH foundation, we have completely digitised the museum pathology specimens.

Over the years, our department accumulated large numbers of glass slides and Kodachrome slides, which were poorly preserved in disorganised boxes stored at different locations. We organised a team of residents and hired three summer students to digitally scan these historical teaching materials and categorised them into organ systems.

Between 2012 and 2018, the department produced three text books: 'Gross Morphology of Common Human Disease', 'Pathology Review and Practice Guide' and 'Transplant Pathology', all of which have become popular references for pathologists and trainees across the world. ${ }^{30-32}$ These new successful initiatives have enhanced the department's position as a leader in pathology education.

Review courses, update courses, CME conferences and textbooks can help to further enhance the leadership role of the department in pathology education and promote the visibility of the department on the national and international stage. Our department runs an annual McGill Cytopathology Review course with attendees from all over the world.

Lessons learnt:

1. Having a 'teaching set' from past collections facilitates learning for the trainees.

2. Well-organised teaching materials can be published and promote the reputation of the department.

3. This process also teaches our trainees and young pathologists the value of establishing their own 'teaching collections'.

\section{RESEARCH}

The increase in service volume and complexity, the staff shortage, the emphasis on turnaround time and clinical efficiency and the fee-for-service system were major obstacles to pathologists conducting research. Difficulties in obtaining research funding (in 2017, the NIH grant success rate was $<18.7 \%$, while the CIHR success rate was $15 \%$ ) were major obstacles for basic science research in the department. ${ }^{334}$ An academic pathology department has an important 
role in supporting tissue-based research for the local research community.

To increase the research capacity, on the basic science front, we recruited to the department scientists that were worldwide leaders in molecular and cell biology, melanoma, ovarian cancer, brain cancer and colon cancer research. On the clinical front, we recruited to the department clinician-scientist in prostate cancer, pancreatic cancer, head and neck tumour, neurodegenerative disorder and lung cancer research. These recruits have laid the foundation for an academic department for the next few decades. Twelve associate members with wet research laboratories were invited to join the department of pathology. We established five core facilities: the histopathology research platform at the MUHC research institute, the pathology and molecular pathology research cores at the Lady Davis research institute, the pathology-imaging research core at the Duff Medical Building and the neuropathology research core with tumour banking facility at the Montreal Neurological Institute.

To facilitate research activities within and outside the department, we established a statistics and project design course. We established a research fund to support pulling blocks and slides, statistical analysis, ethics applications, grant review, manuscript editing and project operating costs for pathologists. We recruited an administrator to facilitate the bioethics applications and the internal review of grant applications. We compiled the research projects and research interests of our medical scientific staff and made this information available to our trainees.

To promote academic culture, we established a monthly scientific lecture series with international renowned external and internal speakers, which ensure our staff are updated with new developments in the field and also encourage collaboration at both the international and local levels. We designated $\$ 50 \mathrm{~K}$ to fund a departmental annual research competition to support five small projects with one receiving $\$ 20 \mathrm{~K}$, two receiving $\$ 10 \mathrm{~K}$ and two receiving $\$ 5 \mathrm{~K}$. We embed research into the residency training curriculum. All our residents are offered a biostatistics course as part of their training. All our residents are required to conduct at least one research project during their training and are encouraged to enrol into a graduate programme, that is, do a master's or PhD degree during their residency. We hold an annual departmental research day to allow our trainees to present their work and celebrate their successes. We give out awards to our trainees who attend and present at national and international scientific conferences.

In 2017, we officially established an Experimental Pathology Unit (EPU) in the department. We defined our signature research programme on diseases with high fatality such as ovarian cancer, brain tumours, asthma, pancreatic cancer and melanoma. Pathologists in our department are involved in the banking of tissue for their relevant subspecialty area. In our department, every clinical subspecialty has a 'sandwich' research structure, where the basic research scientists and their research laboratories serve as the 'foundation', pathologists as the 'meat' and graduate students, residents and fellows as the 'top'. This 'sandwich' structure helps to promote subspecialty-based translational research through effective collaboration between pathologists and basic research scientists.

To facilitate collaboration, using the Chair's start-up fund, a research assistant was hired to pull out tissue blocks and cut blank slides to support researchers at McGill, within and outside the department of pathology. We also provided training to research assistants from different research laboratories to appropriately access tissue specimens. In addition, we supported tissue banking tumour specimens of breast, brain, liver and pancreas and so on. We incorporated the histopathology platform of the MUHC research institute with the MUHC Department of Pathology to support tissue-based research at McGill. Through supporting research and promoting collaborations with investigators in other departments, we effectively enhanced our own reputation and improved external relationships with the McGill research community.

The department's research funding increased from 2.5 million dollars/year to over 20 million dollars/year. In 5 years, we were able to raise over six million dollars to support academic activities of the department. These joint approaches have significantly increased the academic output of our department as demonstrated by a steady increase in high impact publications. In 2017, the department had 157 peer reviewed publications with a mean impact factor 6.06 compared with the mean impact factor of 3.78 in 2013. The McGill department of pathology has gradually regained its reputation as one of the leading research-intensive pathology departments in the world.

Lessons learnt:

1. Each department should consider defining its own signature research programme that will be the 'brand' of the department.

2. Department needs to establish a system to support research, which include infrastructure (eg, core research facilities), process (eg, grant review, ethics approval), finance (such as start-up funds) and people (such as research assistants and an administrative coordinator).

3. Department should capitalise on its specialty advantage so that it can be the hub of tumour banking and tissue-based research collaborations.

In summary, we have shared our experience in revitalising an academic pathology department. Although positive experiences are shared in this article, we admittedly made a number of mistakes during our journey not herein elaborated on. We hope this exercise will inspire other leaders to share their perspectives in transforming their department. Only by doing so can we jointly improve our discipline, for the benefit of our trainees and our patients.

\section{Take home messages}

Vision: clear, focused, idealistic and realistic, challenging and inspiring, shared preferred future.

- Plan: Specific (what, who, when), measurable, time-bound, accountable.

- Resources: infrastructure, finance, process, people.

- People: recruitment, retention, team building, mentoring/ developing, performance appraisal.

- Culture: collegial, innovative, academic, discipline, fair, transparent, effective communication.

\section{Handling editor Tahir S Pillay.}

Contributors All authors contributed to the planning, conduct and reporting of the work described in the article. All authors contributed to the writing and approved the final version of the manuscript.

Funding The authors have not declared a specific grant for this research from any funding agency in the public, commercial or not-for-profit sectors.

Competing interests None declared.

Patient consent Not required.

Provenance and peer review Not commissioned; internally peer reviewed.

\section{REFERENCES}

1 Departement of pathology. 2018. Available: https://www.mcgill.ca/pathology/about/ history [Accessed 7 Jul 2018]. 
2 McGill. Brief history of medicine at McGill. 2018. Available: https://www.mcgill.ca/ medicine/about/glance/history [Accessed 7Jul 2018].

3 Tait MN. Canadian medical schools: two centuries of history. Montreal Harvest House, 1993.

4 SLE - Spécialistes A - ANATOMO-PATHOLOGIE. 2018. Available: http://www.ramq. gouv.qc.ca/SiteCollectionDocuments/professionnels/manuels/170-sle-specialistes/ 011_a_anatomo_patho_sle_spec.pdf [Accessed 30 Aug 2018].

5 Canada. Berkley center for religion, peace, and world affairs, 2018.

6 Collins J. Good to Great: why some companies make the leap... and others don't? 1st edn, 2001.

7 Workload and Workforce Committee of the CAP-ACP. Workload measurement guidelines. Canadian association of pathologists. 2014. Available: https://www. cap-acp.org/cmsUploads/CAP/File/CAP-ACP\%202014\%20Workload\%20FINAL.pdf [Accessed 7 Jun 2018].

8 Quebec. 2018. Available: http://www.ramq.gouv.qc.ca/fr/professionnels/medecinsspecialistes/facturation/anatomo-pathologie/Pages/anatomo-pathologie.aspx\#charge/ [Accessed 1st Sep 2018].

9 Rosy Cancer Network. 2018. Available: https://www.mcgill.ca/rcr-rcn/ [Accessed 1st Sep 2018].

10 F Forsyth, Donelson R. Group dynamics. 5th edn. Boston, MA: Wadsworth Cengage Learning, 2009.

11 Mayer B. The dynamics of conflict: a guide to engagement and intervention. 2nd ed. San Francisco, CA: Jossey-Bass, 2012.

12 Drucker PF. People and performance: the best of peter drucker on management. Routledge, 1995.

13 Isouard G. Quality of pathology services: new strategic directions required. Int J Health Care Qual Assur 2013;26:510-21.

14 Church DL, Hall P. Centralization of a regional clinical microbiology service: The Calgary experience. Can I Infect Dis 1999;10:393-402.

15 Olsen K. The first 110 years of laboratory automation: technologies, applications, and the creative scientist. J Lab Autom 2012;17:469-80.

16 Fryer AA, Smellie WS. Managing demand for laboratory tests: a laboratory toolkit. J Clin Pathol 2013;66:62-72.

17 George ML. Lean six sigma: combining six sigma quality with lean production speed 1st ed. McGraw-Hill Education 2002.

18 Singh M, Pal TR. Voice recognition technology implementation in surgical pathology: advantages and limitations. Arch Pathol Lab Med 2011;135:1476-81.
19 Wright JR, Shokeir MO, Joseph JJ. Late autopsy reports: the calgary so lution. Can J Pathol 2011:3:26-30.

20 Barrows H, Tamblyn R. Problem-based learning: an approach to medical education. Medical education. Volume 1. New York: Springer Publishing Company, 1980.

21 Colliver JA. Effectiveness of problem-based learning curricula: research and theory. Acad Med 2000;75:259-66.

22 CACMS standards and elements. Committee on accreditation of canadian medical schools. 2018. Available: https://cacms-cafmc.ca/accreditation-documents/20162017/standards-and-elements [Accessed 6th Aug 2018].

23 ASMC.https://afmc.ca/data-and-analysis/graduation-questionnaire

24 Vessey JK, Davies G, Driver JC, et al. Guiding principles for graduate student supervision. Canadian Association of Graduate Studies, 2008.

25 Folberg R, Antonioli DA, Alexander CB. Competency-based residency training in pathology: challenges and opportunities. Hum Pathol 2002;33:3-6.

26 Maedler C, Florianova L, Aleynikova 0. Implementation of the multiple mini interview for anatomical pathology resident selection -The McGill University experience. Montreal, QC, Canada: Canadian Association of Pathology meeting, 2015.

27 Maedler C, Florianova L, Zolotarov P. Towards competency by design: establishing a 'transition to pathology' rotation for PGY1 residents. . Montreal, QC, Canada: Canadian association of pathology meeting, 2015: 20. 24.

28 Rivera B, Castellsagué E, Bah I, et al. Biallelic NTHL1 Mutations in a Woman with Multiple Primary Tumors. N Engl J Med 2015;373:1985-6.

29 Florianova L, Aguilar-Mahecha A, Lafleur J, et al. Prediction of neoadjuvant treatment response in triple-negative breast cancer by evaluation of stromal tumor-infiltrating lymphocytes : one university-affiliated hospital experience. Donald W. Penner award for best poster by a resident. Montreal, QC, Canada: Canadian Association of Pathology meeting, June 20-24 2015

30 Gao ZH. Pathology review and practice guide. 2nd edition. Edmonton: Brush Education Inc, 2017.

31 Michel RP, Berry GJ. Pathology of transplantation: a practical diagnostic approach. Switzerland: Springer International Publishing, 2016.

32 Gao ZH. Gross morphology of common diseases. Edmonton, Canada: Brush Education Inc. In Press.

33 Extramural Nexus NIH. Impact of teams receiving NIH Funding. 2017. Available: https://nexus.od.nih.Gov

34 Canadian Institutes of Health Research. Foundation grant and project grant results. 2017. Available: http://www.cihr-irsc.gc.Ca 